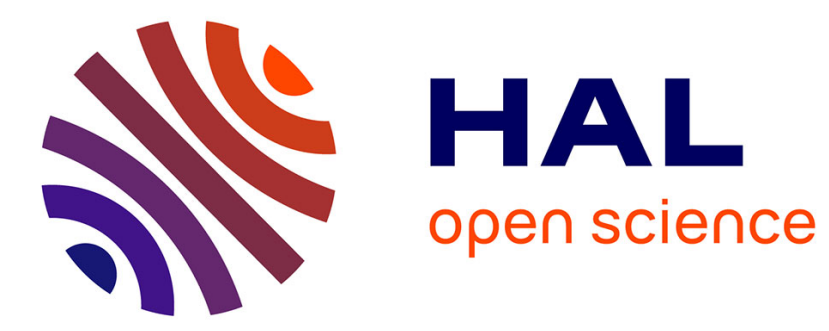

\title{
Capabilities and Affordances in the ICT4D Context
}

Devinder Thapa, Yingqin Zheng

\section{To cite this version:}

Devinder Thapa, Yingqin Zheng. Capabilities and Affordances in the ICT4D Context: Similarities, Differences, and Complementarities. 15th International Conference on Social Implications of Computers in Developing Countries (ICT4D), May 2019, Dar es Salaam, Tanzania. pp.49-59, 10.1007/978-3030-19115-3_5. hal-02281308

\section{HAL Id: hal-02281308 https://hal.inria.fr/hal-02281308}

Submitted on 9 Sep 2019

HAL is a multi-disciplinary open access archive for the deposit and dissemination of scientific research documents, whether they are published or not. The documents may come from teaching and research institutions in France or abroad, or from public or private research centers.
L'archive ouverte pluridisciplinaire HAL, est destinée au dépôt et à la diffusion de documents scientifiques de niveau recherche, publiés ou non, émanant des établissements d'enseignement et de recherche français ou étrangers, des laboratoires publics ou privés.

\section{(c)(1)}

Distributed under a Creative Commons Attribution| 4.0 International License 


\title{
Capabilities and Affordances in the ICT4D Context Similarities, Differences, and Complementarities
}

\author{
Devinder Thapa ${ }^{1}$ and Yingqin Zheng ${ }^{2}$ \\ ${ }^{1}$ Department of Information Systems \\ University of Agder, Kristiansand, Norway \\ devinder.thapa@uia.no \\ ${ }^{2}$ School of Management Royal Holloway \\ University of London, Surrey, UK \\ yingqin.zheng@rhul.ac.uk
}

\begin{abstract}
The paper examines two concepts that have been frequently used in Information and Communications Technologies for Development (ICT4D) research, capabilities and affordance. We seek to delineate their similarities, their differences, and their accurate application in ICT4D. Both concepts connote a space of opportunities, both are relational between artefact and human agency when applied in ICT4D, and both entail potential rather than actualisation of possibilities. By comparing the two at some length, we hope to generate a more refined understanding of both capabilities and affordance, as well as how they could be more accurately applied in ICT4D.
\end{abstract}

Keywords: capabilities, affordance, agency, ICT4D

\section{Introduction}

A debate is ongoing in Information and Communication Technology for Development (ICT4D) research regarding exploring the link between ICT and some kind of development (Walsham, 2012, 2017). There has been extensive discussion of development in ICT4D, namely, what is the end goal of ICT4D (Kleine, 2010; Thapa \& Sæbø, 2014; Walsham, 2017; Zheng \& Walsham, 2008; Zheng et al., 2018). Another question concerns how to unfold the black box of ICT in ICT4D (Hataka, Thapa, \& Sæbø, 2016). After all, ICT4D requires us to take the technological artefacts seriously.

In this paper, we compare two theories—affordance theory and Sen's capability approach (CA) —and seek to delineate their similarities, differences, and accurate applications in ICT4D. These specific theories are compared because both concepts imply a space of opportunities, both are relational between artefact and human agency, and both entail potential rather than actualisation of possibilities. Both concepts have been widely used in the ICT4D literature, albeit for different purposes. It can be confusing at times because the concepts often are understood as a set or as subsets of each other given their similarities, and various attempts have been made to merge the two (Hatakka et al., 2016; Faith, 2018). By comparing the two theories, we 
seek to present a more nuanced understanding of both concepts, especially for those unfamiliar with one or both.

In subsequent sections, we first introduce the origin and definition of the two concepts, followed by their similarities and differences. We then also discuss their limitations and how they might complement each other.

\section{Sen's Capability Approach}

The CA originates from the field of development economics (Sen, 1992, 2000) with a focus on the agency and well-being of individuals and a concern for social arrangements that can enable individuals to live lives they have reason to value. In the ICT4D context, the CA has been used to theorise a human-oriented development paradigm (Thapa, Sein, Sæbø, 2012; Zheng, 2009). One’s capability set can be understood as a space of opportunities that constitutes a valuable life to an individual. The external boundary of the space is defined by structural conditions, such as social, institutional, and cultural conditions, that shape the availability of opportunities.

In the CA, capabilities and functionings are the two main concepts. Capability is defined as "a set of vectors of functionings, reflecting the person's freedom to lead one type of life or another" (Sen, 1992, p. 40). Capabilities refer to the set of valued choices an individual has (e.g. to be educated, to be healthy, or to be respected). Functioning refers to an individual's actualised capabilities. Individuals are active agents who shape their own lives and help others shape theirs (Sen, 2000). The focus of the CA, therefore, is on the expansion of individuals' well-being and agency freedom, as well as how individuals' agency and social arrangements can improve their quality of life.

The conversion of a commodity (e.g. ICT) to capabilities is contingent on three types of conversion factors (Robeyns, 2005): personal (e.g. age, literacy, and health), social (e.g. norms, policies, rules, regulations, and cultural issues), and environmental (e.g. geographic location and climate, as well as infrastructure). These factors influence the availability of capabilities, i.e. valued opportunities, and the ability for people to actualise available choices.

When applied in ICT4D, one major weakness of the CA is that it does not explicitly theorise on technology. Instead, technology is likely to be treated as a commodity in the CA (Zheng, 2009; Thapa \& Hatakka, 2017). Thus, ICTs are often "black-boxed" and seen as neutral, which can lead to positive outcomes (Zheng \& Stahl, 2011). Furthermore, the CA has little to offer when considering the process through which capabilities could be generated from ICT.

\section{Affordance Theory}

The concept of affordance, on the other hand, originates from the field of ecological psychology and is concerned with the action possibilities afforded in the relationship between individuals and their environment (Gibson, 1979). According to Gibson (1979, p. 127), "[t]he affordances of the environment are what it offers the animal, what it provides or furnishes, either for good or ill. It implies the complementarity of 
the animal and the environment”. Gibson's ideas moved from the natural environment to artificial objects such as tools. He also insisted that artificial affordances are no different from naturally occurring affordances. This focus on the tools makes the theory of affordance relevant for information systems (IS) research (Thapa \& Sein, 2018).

We derive the definition of affordances from IS because of its focus on people, technology, and organisation. In IS, affordances are defined as "the possibilities for goal-oriented action afforded to specified user groups by technical objects” (Markus \& Silver, 2008, p. 622), in which action possibilities depend on the relationship between systems and users in the context of the kind of ICT used. The affordance perspective suggests that people are more concerned with the action possibilities enabled by the technology than they are with the properties of the technology itself (Majchrzak \& Markus, 2013). For example, visibility, editability, persistence, and association could be considered functional affordances for social media (Treem \& Leonardi, 2013), whereas commenting, accessibility, viewability, and validation are associated with wikis (Mansour, Askenas, \& Ghazawneh, 2013). Some scholars also suggest group-level affordances; for example, Majchrzak, Faraj, Kane, and Azad (2013) argue that an online knowledge-sharing platform affords the following possibilities: metavoicing, triggered attending, network-informed associating, and generative role-taking.

Affordances can provide a relational middle ground between technological determinism and social constructivism (Faraj \& Azad, 2012; Leonardi \& Barley, 2010; Robey, Anderson, \& Raymond, 2013), in the sense that affordances do not determine how people will use a technology. At the same time, however, technology's potential uses are not fully open-ended due to material limitations (Thapa \& Sein, 2018).

A criticism is that the affordance concept has often been stripped of relational character and reduced to properties of the object matched to the "effectivities" of the subject (Bloomfield, Latham, \& Vurdubakis, 2010). This could be called a realist view of affordance (Robey et al., 2013), which often refers to actions closely associated with functionalities of artefacts and often implies a linear causality in the sequence of existence-perception-actualisation (Bernhard et al., 2013). In comparison, a relational view of affordance (Robey et al., 2013) suggests that technological affordances "are inextricably bound up with specific, historically situated modes of engagement and ways of life" (p. 415; Bloomfield et al., 2010). For example, the affordances of a pair of chopsticks may be obvious to a native Chinese person but hardly perceivable to someone who has not encountered them before. Indeed, in this case, affordances to pick up food only become available when an individual acquires the skill of using chopsticks.

Therefore, affordances are not always directly perceivable, and the actualisation of the affordances depends on the interaction between the artefact and the actors situated in the context (Bernhard, Recker, \& Burton-Jones, 2013), including social and cultural contexts (Thapa \& Sein, 2018). However, affordance theory itself offers little explanation as to how affordances are actualised and how different sociotechnical factors enable or inhibit the actualisation process. Moreover, affordance theory pays no attention to the consequences of actualisation. 
In ICT4D research, where we are more concerned with the process and impact of technological adoption in broader social life, i.e. beyond the immediate interaction between artefact and users, it may be more useful to discuss socialised affordances (Zheng \& Yu, 2016) rather than only functional affordances. Socialised affordances explicitly take into account conversion factors, such as personal, social, and environmental factors (Bloomfield et al., 2010; Hausvik \& Thapa, 2017), as emphasised in the CA, as well as social practices and processes as conversion mechanisms. Zheng and Yu (2016) provide an example in their case study of affordances of social media in mobilising a charity programme for rural children in China. Similarly, what Thapa and Sein (2018) identify as affordances of telemedicine, including virtual co-localisability, volunteeribility, and educability, are arguably closer to socialised affordances rather than functional affordances.

\section{Similarities}

Capabilities and affordances have the following similarities: both signify action possibilities, both are relational, and both are contingent on conversion factors. By definition, capabilities and affordances signify possibilities, i.e. opportunities or choices of being and doing, but not the actual outcome or achievement. These possibilities are not essential to the subject, i.e. do not pre-exist in an individual or an artefact and cannot be determined by only assessing the characteristics of an individual or properties of an artefact. Both capabilities and affordances are context specific, i.e. embedded in a specific sociocultural and historical context. As a result, the nature of capabilities and affordances is not deterministic but dynamic, as they change over time. In the absence of contextual information, it can be difficult to identify capabilities and affordances.

It follows that the CA and affordances are arguably ontologically relational (although there are alternative stances on this; e.g. see Lanamäki, Thapa, \& Stendal, 2016). Capabilities, as a space of opportunities, can be understood as relational effects emerging from the configuration of social structures and individual capacity and agency, which is influenced by the relative position of the individual in the social environment (Smith \& Seward, 2009). Technologies, or material artefacts, can be incorporated in this configuration but are not essential to the CA (see section 6).

In comparison, affordances are action possibilities arising from the perception and interaction of users with artefacts-conditioned by the functional properties to the object and the individual capacity_-situated in a particular social context (Volkoff \& Strong, 2013). The same object may provide different affordances to different people in different contexts. Similarly, the same person may enjoy different capability sets if situated in a different social environment, whereas people with different individual capacities and relational resources usually have different sets of choices under the same social structure (Kleine, 2010).

Therefore, both affordances and capabilities are contingent on conversion factors. For Sen, this is why it is crucial to differentiate capabilities from commodities. For example, a computer may be perceived to offer a range of technical affordances to a person, e.g. to process documents or to browse the web. The actualisation of those 
affordances, however, is contingent on the person's capacity, attitude, and social conditions.

There are occasions when capabilities and affordances might overlap, especially when affordances are socialised beyond functional affordances through social processes and practices (Zheng \& Yu, 2016) and are converted into functionings that an individual considers valuable. For example, given the conversation factors of individual skills and roads in reasonable conditions, a bicycle may be considered to provide the affordance of mobility, which could also be a capability that a person values.

\section{Differences}

Despite the similarities, there are some fundamental differences between these two concepts as described in the following three aspects.

The CA is philosophically anthropocentric and humanistic, which focuses on an individual's well-being and agency. Capability reflects the real opportunities that a person has to lead a life that he or she has reason to value (Zheng, 2009). It should be noted that Sen explicitly differentiates "value" from "desire" or "happiness" as follows: "valuation is a reflective activity in a way that 'being happy' or 'desiring' need not be" (Sen, 1992, pp. 29-30). The emphasis on human agencies and their values is one of the reasons that the CA is considered a normative approach with a fundamental interest in the ethics of development, which is distinct from other evaluative approaches to development that focus on income, utilities, or happiness.

In contrast, affordance is a concept of materiality that centres on the potential utility of objects. Affordance arises from the properties of an artefact in relation to its design and functionalities. While affordance is relational to human agency, in its original sense, its interest in human values, social conditions, or ethical evaluation, if any, mainly serves the purpose of understanding user behaviour and designing relevant affordances for particular purposes. In particular, functional affordances are mainly concerned with the immediate outcome of human interaction with the artefact (Seidel, Recker, \& Vom Brocke, 2013) rather than broader implications for the individual, communities, or society. Often these implications are outside the scope of consideration or assumed to take place automatically.

Consider e-learning systems, for example. A functional e-learning system may afford the possibilities to access information and educational material that may not otherwise be available and to have virtual interactions with tutors and fellow students (Gros \& García-Peñalvo, 2016). A capability related to such a system is to be educated, which is a much broader and more abstract notion that can be achieved not only through the e-learning system but through years of studying and learning via other means. There is no absolute causality between using the functions of an elearning system and getting educated, as an individual could use the system but not engage with the learning process. In other words, actualisation of an e-learning system's functional affordances does not directly translate into the achieved capabilities of receiving education.

The most critical difference between the two concepts lies in their relationship with social structures. As discussed previously, capability is inherently conditioned by 
social structure and a person's relative position in his or her social network. Although the CA has been criticised for the lack of theorisation on social structure, Sen emphatically argues that "the removal of unfreedoms . . . is constitutive of development” (Sen, 1992, p. xii). In other words, the expansion of an individual's capability set requires not only the enhancement of the his or her well-being and agency, but, more importantly, the removal of deprivation and restrictions that often result from structural and environmental conditions. In contrast, the affordance theory largely remains on the agency level and tends to focus on interventions related to individual skills, aptitudes, and resources (although socialised affordance may allow some conceptual space to take social structures into account).

In the context of ICT4D, affordances seem to be more associated with the "means" (i.e. adoption of ICT) but say little about developmental outcome, which is the "ends". In contrast, the CA is directly concerned with the outcome (e.g. individual well-being), is value-driven, and is normative. Therefore, the affordance theory is very useful in guiding the design of technologies, whereas the CA is often used as an evaluative framework for the social outcome of ICT4D projects.

\section{Complementarities}

Various attempts have been made to integrate the concept of affordance with the CA (Hatakka et al., 2016; Sein, Thapa, Hatakka, \& Sæbø, 2018), but that is not the intention of this paper. The aim of this paper is to clarify the distinction between the two, which may shed light on their relationship and how they can be used appropriately either separately or together.

Building on Smith and Seward's (2009) relational ontology of Sen's CA (discussed in section 4), Oosterlaken (2011) argues that technological artefacts should also be recognised as constituents of human capabilities, in addition to human agency and social structures. She does so by drawing upon Lawson's (2010) conception of technology as an extension of human capabilities, which in turn is derived from the philosophy of technology and science and technology studies (STS). It should be noted that by "human capabilities", Lawson (2010) is not referring to the CA but to capabilities in its common sense. For example, technological artefacts may extend an individual's senses (vision, hearing), abstract thoughts, language functions, or memories.

Lawson (2010) argues that material properties of technical objects, when being enrolled into "particular networks of social and technical interdependences", may possess capacities and powers, which, like social structures, operate with certain causal mechanisms that human agents have to work around and respect when trying to "harness the causal power of such objects" (p. 215). Meanwhile, technological objects embody and extend human intentions, values, and social relations "through a process of human interventions” (p. 214). Of course, this is nothing new for those familiar with STS or actor-network theory. These causal powers or mechanisms are exactly what the notion of affordance entails - they are not deterministic but generate certain causal effects when enacted. In other words, it is reasonable to argue that technological affordances, when enrolled in a sociotechnical network in a meaningful 
way, have the potential to extend human capabilities, which may ultimately enhance or diminish valuable choices.

Therefore, building on Oosterlaken (2011), technological affordances could be conceived as a relational component of one's capability set (in the sense of the CA), the actualisation of which affects both the achieved functionings and capabilities (valued opportunities) that an individual enjoys. Not only do technological affordances condition the action possibilities of human agents, they are also often entangled with existing power relations and social structures that set a boundary, albeit in flux, for individuals' substantive freedom (Zheng \& Stahl, 2011). On the other hand, the actualisation of affordances may also affect the positionality of human agents in relation to social structures, thereby transforming or reproducing their capability to lead valuable lives. For example, the technical design of computers presumes a certain literacy and way of working stemming from industrialised societies, which have often been imposed on users and organisations in other contexts. The actualisation of these functional affordances must rely on the cooperation of users' practices, which then changes their access to information, connectivity to social networks, and capacity to perform certain tasks, thereby possibly contributing to their valued choices to be active members of a community, to participate in public affairs, or to build a livelihood. It is important to reiterate, however, that actualised affordances do not automatically translate into higher functionings or capabilities.

\section{Applications in ICT4D}

Table 1 shows the comparison of the two theories as discussed above. By exploring the similarities and differences of the CA and the affordance lens at some length, it is clear that they focus on different aspects of ICT4D and serve different purposes. For example, the CA is more focused on the evaluation of individual choices (ends), whereas affordances centre on the direct interaction between technology (means) and goal-oriented actors. The CA sees artefacts as neutral resources and puts an emphasis on conversion factors, which conditions how ICTs might or might not lead to capabilities. The affordance lens pays less attention to broader social contexts that actors are situated in and is completely silent on how actualisation of affordance may give rise to any developmental outcome. Using both theories together may offer a better understanding of whether and how human technology interaction actually advances an individual's pursuit of a valuable life by enhancing his or her well-being and agency freedom.

For ICT4D researchers, it should be noted that the affordances lens, especially functional affordances, entails a narrow focus on technology adoption in the immediate context of the interaction. This may be useful if the objective of the research is to design an artefact or to explore how different designs give rise to different behaviours and consequences. However, care must be taken when making assertions about developmental outcomes based on a study of functional affordances. Nevertheless, by socialising affordances, namely, focusing on the practices and processes that convert functional affordances to affordances-in-practice (Zheng \& Yu 2016), ICT4D researchers can avoid technology determinism and shed light on the 
complexity of ICT actualisation processes in different contexts. Moreover, affordances can both enable and constrain someone's goal, making it particularly important for ICT4D researchers to be sensitive to both effects of technologies. By connecting with the CA- especially in terms of what users' value and aspire to-and with the three sets of conversion factors, the affordances lens could provide better design guidance which generates possibilities that contribute to sustainable development.

For ICT4D studies that use the CA and would also like to take technology more seriously, it should be noted that technology is not neutral, and its affordances are bundled with human agency. By examining the opportunities and barriers to actualise technological affordances, we could better understand, in a given social and physical environment, what type of ICTs to use or how to design ICTs that are sensitive to actors' attitudes and skills and how to facilitate the conversion from action possibilities to the expansion of substantive freedom.

Table 1. Juxtaposition of Capability and Functional Affordance

\begin{tabular}{|c|c|c|}
\hline Dimensions & Capability & Functional Affordance \\
\hline Origin and focus & $\begin{array}{l}\text { Originates from the field of } \\
\text { development economics; } \\
\text { Centres on the valued } \\
\text { opportunities and choices } \\
\text { available to an individual; } \\
\text { Focuses on well-being and } \\
\text { agency of individuals as the } \\
\text { end goal of development } \\
\text { Considers social arrangements } \\
\text { that enable individuals to } \\
\text { lead a life they have reasons } \\
\text { to value; } \\
\text { Emphasise conversion factors } \\
\text { (e.g. individual, social, and } \\
\text { environment) possibly } \\
\text { acting as enablers or } \\
\text { inhibitors } \\
\text { Can be understood as space of } \\
\text { opportunities with the upper } \\
\text { limit of the space defined by } \\
\text { structural conditions } \\
\text { Concerned with the removal of } \\
\text { unfreedom } \\
\text { ICT often "black-boxed" and } \\
\text { seen as something neutral } \\
\text { that can lead to positive } \\
\text { outcomes }\end{array}$ & $\begin{array}{l}\text { Originates from the field of } \\
\text { ecological psychology } \\
\text { Concerns the action } \\
\text { possibilities afforded in } \\
\text { the relationship between } \\
\text { individuals and the } \\
\text { environment } \\
\text { Focuses on the effectivities } \\
\text { and utility of artefacts, } \\
\text { given the sociocultural } \\
\text { context and resources } \\
\text { available, and } \\
\text { individuals' abilities to } \\
\text { perceive affordances that } \\
\text { lead to goal fulfilment } \\
\text { Does not consider the effect } \\
\text { of the outcome of the } \\
\text { actualisation of action } \\
\text { possibilities (can be for } \\
\text { good or ill) } \\
\text { Associated with artefacts- } \\
\text { affordances of an object } \\
\text { Perception and actualisation } \\
\text { of affordances dependent } \\
\text { on the relationship } \\
\text { between the system and } \\
\text { the actors in the context }\end{array}$ \\
\hline
\end{tabular}




\begin{tabular}{|c|c|c|}
\hline & & $\begin{array}{l}\text { in which ICT are used } \\
\text { Perception and actualisation } \\
\text { of affordances influenced } \\
\text { by personal, } \\
\text { sociocultural, and } \\
\text { historical contexts }\end{array}$ \\
\hline Similarities & $\begin{array}{l}\text { Space of possibilities enhanced } \\
\text { by structural arrangements } \\
\text { and individual agency } \\
\text { Both dispositional and } \\
\text { relational: contingent on and } \\
\text { human agency and aptitude } \\
\text { as well as individuals' } \\
\text { positionality within a social } \\
\text { structure } \\
\text { Context specific } \\
\text { Potential not actual } \\
\text { achievement } \\
\text { Dynamic and could change } \\
\text { over time }\end{array}$ & $\begin{array}{l}\text { Action possibilities afforded } \\
\text { by properties of an } \\
\text { artefact } \\
\text { Both dispositional and } \\
\text { relational: contingent on } \\
\text { properties of an object } \\
\text { and the agency of goal- } \\
\text { oriented actors } \\
\text { Context specific } \\
\text { Potential not actual } \\
\text { achievement } \\
\text { Dynamic and could change } \\
\text { over time }\end{array}$ \\
\hline Differences & $\begin{array}{l}\text { Vectors of choices that can be } \\
\text { turned into achieved } \\
\text { functioning } \\
\text { Human-centred: capabilities } \\
\text { are defined by a person or a } \\
\text { group of people } \\
\text { Value-driven, concerned with } \\
\text { the freedom to lead a life } \\
\text { that one has reasons to value } \\
\text { Normative and focus on ends } \\
\text { of development } \\
\text { Concerned with a person's life } \\
\text { as a whole (well-being and } \\
\text { agency) }\end{array}$ & $\begin{array}{l}\text { Action possibilities that may } \\
\text { or may not be actualised } \\
\text { A notion of materiality } \\
\text { associated with design } \\
\text { and functionalities } \\
\text { Concerned with immediate } \\
\text { action outcome, directly } \\
\text { associated with artefacts } \\
\text { Value-neutral and focus on } \\
\text { means of development } \\
\text { Could be arguably } \\
\text { conceived as extending } \\
\text { 'human capabilities' in its } \\
\text { common sense, } \\
\end{array}$ \\
\hline Limitations & $\begin{array}{l}\text { Does not include artefacts } \\
\text { explicitly, but talks about } \\
\text { commodities; } \\
\text { Not explicit with how, i.e. the } \\
\text { process where capabilities } \\
\text { could be generated; } \\
\text { Insufficient theorisation on } \\
\text { social structures }\end{array}$ & $\begin{array}{l}\text { Does not consider end } \\
\text { results (good or ill), and } \\
\text { also how conversion } \\
\text { factors enable or inhibit } \\
\text { action possibilities } \\
\text { Limited understanding of } \\
\text { contextual factors (e.g. } \\
\text { social, political, personal, } \\
\text { and environmental), } \\
\text { which can influence the } \\
\text { actualisation process } \\
\text { No theorisation on social }\end{array}$ \\
\hline
\end{tabular}




\begin{tabular}{|l|l|l|}
\hline $\begin{array}{l}\text { Complementarit } \\
\mathrm{y}\end{array}$ & $\begin{array}{c}\text { Can be used to evaluate the } \\
\text { development outcome of } \\
\text { technological adoption } \\
\text { Can complement affordances } \\
\text { by identifying conversion } \\
\text { factors that can enable or } \\
\text { inhibit the process of } \\
\text { actualisation of affordances }\end{array}$ & $\begin{array}{c}\text { Can be conceived as a } \\
\text { constituent of capability, } \\
\text { which interacts with } \\
\text { human agency to shape } \\
\text { social structure and to } \\
\text { change the level of } \\
\text { functioning and space of } \\
\text { opportunities }\end{array}$ \\
& Opportunity to be educated & $\begin{array}{c}\text { Accessibility to online } \\
\text { educational material }\end{array}$ \\
\hline Examples & \multicolumn{2}{|}{} \\
\hline
\end{tabular}

\section{References}

Bernhard, E., Recker, J. C., \& Burton-Jones, A. (2013). Understanding the actualisation of affordances: A study in the process modeling context.

Bloomfield, B. P., Latham, Y., \& Vurdubakis, T. (2010). Bodies, technologies and action possibilities: When is an affordance? Sociology, 44(3), 415-433.

Faith, B. (2018). Gender, Mobile, and Mobile Internet| Maintenance Affordances, Capabilities and Structural Inequalities: Mobile Phone Use By Low-Income Women. Information Technologies \& International Development, 14, 66-80.

Faraj, S., \& Azad, B. (2012). The materiality of technology: An affordance perspective. Materiality and organizing: Social interaction in a technological world, 237-258.

Gibson, J. (1979). The theory of affordances The Ecological Approach to Visual Perception (pp. 127-143). In: Boston: Houghton Miffin.

Gros, B., \& García-Peñalvo, F. J. (2016). Future trends in the design strategies and technological affordances of e-learning. In M. Spector, B. B. Lockee, \& M. D. Childress (Eds.), Learning, Design, and Technology: An International Compendium of Theory, Research, Practice, and Policy, (pp. 1-23).

Hatakka, M., Thapa, D. \& Sæbø, Ø. (2016). A framework for understanding the link between ICT and development: How affordances influence capabilities. In SIG GlobDev, Dublin, December 112016.

Hausvik, G. I., \& Thapa, D. (2017). "What You See is Not What You Get”Challenges in Actualisation of EHR Affordances. Paper presented at the International Conference on Information Systems, Seoul, South Korea.

Kleine, D. (2010). ICT4WHAT?-Using the choice framework to operationalise the capability approach to development. Journal of International Development, 22(5), 674-692.

Lanamäki, A., Thapa, D. and Stendal, K. (2016). When Is an Affordance? Outlining Four Stances. In L. Introna, D. Kavanagh, S. Kelly, W. Orlikowski \& S. Scott (Eds.), Beyond Interpretivism? New Encounters with Technology and Organization: IFIP WG 8.2 Working Conference on Information Systems 
and Organizations, IS\&O 2016, Dublin, Ireland, December 9-10, 2016, Proceedings (pp. 125-139). Cham: Springer International Publishing.

Lawson, C. (2010), “Technology and the extension of human capabilities”, Journal for the Theory of Social Behaviour, Vol. 40 No. 2, pp. 207-223.

Leonardi, P. M., \& Barley, S. R. (2010). What's under construction here? Social action, materiality, and power in constructivist studies of technology and organizing. Academy of Management Annals, 4(1), 1-51.

Majchrzak, A., \& Markus, M.L. (2013 ). Technology affordances and constraints theory of Management Information Systems . In Kessler, E.H. (Ed.). Encyclopedia of Management Theory (pp. 832 - 836). Sage, Thousand Oaks

Majchrzak, A., Faraj, S., Kane, G.C. and Azad, B. (2013), "The Contradictory Influence of Social Media Affordances on Online Communal Knowledge Sharing”, Journal of Computer-Mediated Communication, Vol. 19 No. 1, pp. 38-55.

Mansour, O., Askenas, L. and Ghazawneh, A. (2013), "Social Media and Organizing - An Empirical Analysis of the Role of Wiki Affordances in Organizing Practices", Proceedings of International Conference of Information Systems 2013, Milan, Italy

Markus, M. L., \& Silver, M. S. (2008). A foundation for the study of IT effects: A new look at DeSanctis and Poole's concepts of structural features and spirit. Journal of the Association for Information systems, 9(10/11), 609.

Oosterlaken, I. (2011). Inserting technology in the relational ontology of Sen's capability approach. Journal of Human Development and Capabilities, 12(3), 425-432.

Robey, D., Anderson, C., \& Raymond, B. (2013). Information technology, materiality, and organizational change: A professional odyssey. Journal of the Association for Information systems, 14(7), 379.

Robeyns, I. (2005). The Capability Approach: a theoretical survey. Journal of Human Development, 6(1), 93-114.

Seidel, S., Recker, J. C., \& Vom Brocke, J. (2013). Sensemaking and sustainable practicing: functional affordances of information systems in green transformations. Management Information Systems Quarterly, 37(4), 12751299.

Sein, M. K., Thapa, D., Hatakka, M., \& Sæbø, Ø. (2018). A holistic perspective on the theoretical foundations for ICT4D research. Information Technology for Development, 1-19. doi:10.1080/02681102.2018.1503589

Sen, A. (1992). Inequality Reexamined: Cambridge University Press, Cambridge.

Sen, A. (2000). Development as Freedom: Oxford University Press.

Smith, M.L. and Seward, C. (2009), “The Relational Ontology of Amartya Sen's Capability Approach: Incorporating Social and Individual Causes”, Journal of Human Development and Capabilities, Vol. 10 No. 2, pp. 213-235.

Thapa, D., \& Hatakka, M. (2017). Understanding ICT in ICT4D: An Affordance Perspective. Paper presented at the Proceedings of the 50th Hawaii International Conference on System Sciences. 
Thapa, D., \& Sæbø, Ø. (2014). Exploring the link between ICT and development in the context of developing countries: a literature review. The Electronic Journal of Information Systems in Developing Countries, 64.

Thapa, D., \& Sein, M. K. (2018). Trajectory of Affordances: Insights from a case of telemedicine in Nepal. Information Systems Journal, 28(5), 796-817.

Thapa, D., Sein, M. K., \& Sæbø, Ø. (2012). Building collective capabilities through ICT in a mountain region of Nepal: where social capital leads to collective action. Information Technology for Development, 18(1), 5-22.

Treem, J. W., \& Leonardi, P. M. (2013). Social media use in organizations: Exploring the affordances of visibility, editability, persistence, and association. Annals of the International Communication Association, 36(1), 143-189.

Volkoff, O., \& Strong, D. M. (2013). Critical Realism and Affordances: Theorizing IT-associated Organizational Change Processes. MIS Quarterly, 37(3).

Walsham, G. (2012). Are we making a better world with ICTs? Reflections on a future agenda for the IS field. . Journal of Information Technology, 27(2), 8793.

Walsham, G. (2017). ICT4D research: reflections on history and future agenda. Information Technology for Development, 23(1), 18-41.

Zheng, Y. (2009). Different spaces for e-development: What can we learn from the capability approach? Information Technology for Development, 15(2), 66-82.

Zheng, Y., \& Stahl, B. C. (2011). Technology, capabilities and critical perspectives: what can critical theory contribute to Sen's capability approach? Ethics and Information Technology, 13(2), 69-80.

Zheng , Y., \& Walsham , G. (2008). Inequality of what Social exclusion in the e society as capability deprivation. Information Technology and People, 21(3), 222-243.

Zheng, Y., \& Yu, A. (2016). Affordances of social media in collective action: the case of Free Lunch for Children in China. Information Systems Journal, 26(3), 289313.

Zheng, Y., Hatakka, M., Sahay, S. and Andersson, A. (2018), “Conceptualizing development in information and communication technology for development (ICT4D)”, Information Technology for Development, Vol. 24 No. 1, pp. 1-14. 